\title{
Hormone Therapy for Metastatic Carcinoma of the Prostate: Where Do We Stand?
}

\author{
J.E. Altwein \\ Urologische Abteilung, Krankenhaus der Barmherzigen Brüder, München
}

\begin{abstract}
Almost 60 years after the introduction of androgen withdrawal, which includes surgical castration, for metastatic carcinoma of the prostate the question arises what have we achieved in those years? Hormone therapy is still the mainstay for metastatic carcinoma of the prostate. At the time of diagnosis, $38 \%$ of men with this tumor receive an androgen deprivation as the only form of specific treatment, in addition $20 \%$ receive androgen deprivation neoadjuvantly or adjuvantly, i.e. before or after treating the primary tumor with radical prostatectomy, definitive radiotherapy or brachytherapy. In general, any modality of endocrine manipulation is given with palliative or rarely preventive palliative intent, which describes the systemic treatment following radical prostatectomy for node-positive disease to prolong the time-to-progression. So far, the only indication of its curative potential comes from a retrospective study of the University of Connecticut and is applicable for patients with a localized carcinoma and a Gleason score between 2 and 4 ( $\triangleq$ well-differentiated).
\end{abstract}

When prostate cancer is exposed to endocrine withdrawal for the first time, the majority of the tumor cell clones will respond. These virginal cancers regress due to a distorted mechanism of hormonal signal transduction (fig. 1). This holds also true - as far as hormone responsiveness is concerned - for the hormone therapy of tumors removed by radical prostatectomy or manipulated by a transurethral resection of the prostate, whereas with irradiation the situation is less clear as far as hormone sensitivity is concerned - thus the term pseudo-virginal was coined. Furthermore, it is known that an androgendependent carcinoma of the prostate regresses by apoptosis or programmed cell death by any procedure which reduces the intracellular concentration of dihydrotestosterone by more than $80 \%$.

Following androgen withdrawal the differentiated cells and the tumorigenic stem cells regress, and the former cells prevail by the ratio of 1:2,000 [1]. With progression of the same tumor, the number of androgen-independent stem cells increase extensively, leading to a shift in the ratio between these cells to differentiated cells to 1:200. In addition, there is evidence that the androgen receptor regains nuclear localization soon after castration, but is activated later by an unknown mechanism that increases nuclear androgen receptor content and may cause cellular proliferation in androgen absence. One of the responsible mechanisms applicable for patients being treated with a maximal androgen ablation (= combination of medical or surgical castration plus an antiandrogen) is the modulation of the receptor in a sense that the former androgen receptor becomes promiscuous and responds to an antiandrogen in the same way as to an androgen [2,3].

Orchiectomy removes testosterone, the promotor of prostatic growth. The benefits of orchiectomy are its relative simplicity, safety, low costs, a symptom relief in $70-80 \%$ and a pain relief from bone metastases in $80-90 \%$ of the patients. Furthermore, the prostate shrinks within 2-3 months. There are drawbacks, however, including loss of libido, impotence, and hot flushes. More important, this is an irreversible procedure and quite unacceptable for some patients. So, although its efficacy is the gold standard against which all newer treatments are judged, orchiectomy has been less frequently chosen, particularly as prostate cancer has been diagnosed in younger patients who are still sexually active. Luteinizing hormone-releasing hormone analogues (LH-RHa) are clinically as effective as orchiectomy and show similar side effects (loss of libido, impotence, and hot flushes); comparative studies found a significant improvement in the quality of life with LH-RHa therapy versus orchiectomy. Unlike estrogens, they are not associated with an increased vascular risk.

Following the initial application of LH-RHa, there is a shortlived increase of luteinizing hormone ( $\mathrm{LH})$ and therefore testosterone. After that, the level of LH falls dramatically and within 3 weeks testosterone reaches castration levels. The transient rise in testosterone causes a tumor flare in about $5 \%$ of the patients and may cause worsening symptoms such as bone pain. It is a particular problem in patients with extensive bone metastases and can have potentially serious consequences in patients with spinal metastases where it can lead to spinal cord compression and ultimately paraplegia. This flare phenomenon can be prevented by the administration of antiandrogens 7-10 days before the start of LH-RHa therapy, or concomitantly over the first 3 weeks.

\begin{tabular}{ll}
\hline KARGER & @ 2000 S. Karger GmbH, Freiburg \\
$\begin{array}{l}\text { Fax }+497614520714 \\
\begin{array}{l}\text { E-mail Information@Karger.de } \\
\text { www.karger.com }\end{array}\end{array}$ & $\begin{array}{l}\text { Accessible online at: } \\
\text { www.karger.com/journals/onk }\end{array}$
\end{tabular}

Prof. Dr. med. J. E. Altwein Urologische Abteilung Krankenhaus der Barmherzigen Brüder Romanstraße 93 D-80639 München (Germany) 
Fig. 1. Mechanism of the action of LH-RH on the receptor of the prostate cancer cell.

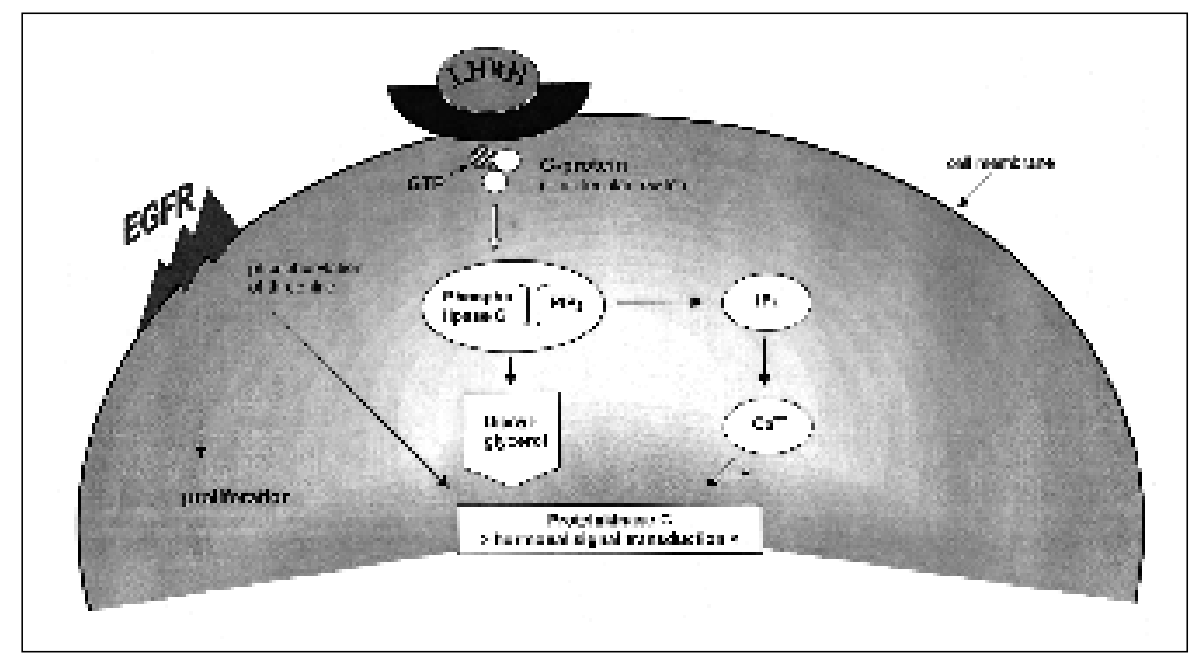

\section{Maximal Androgen Blockade}

Neither surgical nor medical castration with LH-RHa affects adrenal androgen secretion and so prostate cancer cells continue to receive androgenic stimulation in these situations. One has argued this could be responsible for the early progression, which is experienced only 16 months after surgical castration [4]. To prolong survival, maximal androgen blockade was introduced. This modality has been tested in 30 phase III trials including over 8,000 patients showing that the time to progression is postponed by 6 months. The cancer-specific survival is prolonged by $3-6$ months, yielding a survival advantage of $10 \%$ after 5 years (Second Consultation on Prostatic Carcinoma, Committee 9; Paris, June 27-29, 1999).

One has attempted to enhance the efficacy of maximal androgen blockade in adding suramin. Although poorly tolerated in patients with an unfavorable prognosis, $66 \%$ of the men treated experienced a remission which was complete in $6 \%$. Addressing the quality-of-life issue, it was shown in a recent Austrian trial that patients with metastases due to carcinoma of the prostate treated with maximal androgen blockade alone or in combination with epirubicine, the TWIST (= Time Without Symptoms and Toxicity of Treatment) was almost a year longer when epirubicine was added. Likewise, in a study from Israel a 10 -year survival rate close to $50 \%$ was achieved despite bone metastases when 5-FU plus cyclophosphamide was given in combination with the androgen deprivation. These concepts, however, never gained popularity due to the age of the diseased men and the side effects which contrasted the palliative intent.

Another possibility to cope with the development of hormone resistance is delaying the inception of androgen withdrawal. The issue of timing the treatment was given extensive consideration in a Medical Research Council trial which demonstrated that patients being treated immediately versus delayed showed similar results, if tumor-specific survival is the endpoint (76 vs. $80 \%$ ), however, the number of complications was almost twice as high in patients with delayed treatment despite osseous metastases. In choosing the form of endocrine manipulation, the presence of lymph node and/or bone metastases is relevant. First-line hormonal therapy basically means castration or employing a long-acting LH-RHa every 3 months. For the concept of intermittent androgen deprivation, the LH-RHa is inevitable. To lower side effects and costs, intermittent androgen deprivation is advantageous in patients of potential longevity. As far as health-related quality of life is concerned, it is also preferred to surgical castration. It is of note that in experiments these agonists acted directly on the tumor cell. Whether this translates into a benefit for the patient is unclear. Often overlooked is the unacceptable complication rate of the surgical orchiectomy of close to $20 \%$ in some series. LH-RH antagonists, such as cetrorelix, never have been tested in a randomized trial against the agonists, and it is highly unlikely that they are more efficient. If a maximal androgen blockade is the treatment chosen, the pure antiandrogen has to be thoroughly selected to avoid unnecessary side effects such as flutamide-based diarrhea. According to a recent metaanalysis, a combination of medical or surgical castration plus cyproterone acetate is superfluous. Second-line hormone therapy in practice means that the antiandrogen in patients being treated with a maximal antiandrogen blockade ought to be discontinued to experience the so-called androgen withdrawal syndrome. It is expected that roughly a third of patients will experience a $50 \%$ decline of PSA following discontinuation of the antiandrogen. Interestingly enough, if one switches to estrogens as second-line treatment, roughly $50 \%$ of patients respond.

Together with the form of androgen deprivation, one should consider the indication. Patients with an intracapsular prostatic carcinoma do not need any form of androgen ablation at the time of diagnosis. Neoadjuvant androgen deprivation starts 3 months before radical prostatectomy or irradiation. Although in 7 metaanalyzed studies it has been shown that it lowered the pathological stage and particularly decreased the number of positive surgical margins, it is unclear whether this translates into a survival advantage. The efficacy of such a treatment upfront may be enhanced if used over a period of 9 months, however, this definitively reduces the acceptance of the patients waiting for a radical prostatectomy or irradiation.

Entirely unclear is the value of adjuvant therapy. Although evidence is emerging that in the presence of lymph node metasta- 
ses discovered at the time of radical prostatectomy, an immediate androgen deprivation prolongs the time to progression. If the indication for an adjuvant treatment is based on the presence of positive surgical margins or an unfavorable Gleason score (8-10), the advantage is debatable. Particularly so if one considers the potential longevity of these patients, which means that they have to tolerate the side effects of hormonal manipulation for a long time with consequences on their quality of life. A recent EORTC study indicates an advantage if irradiation of locally advanced carcinoma of the prostate is given in conjunction with androgen deprivation, however, it is unknown whether androgen deprivation without irradiation will lead to the same result. The most common form of hormonal therapy in the presence of metastases still is the continuous androgen deprivation achieved through medical or surgical castration with palliative intent. The appealing concept of intermittent androgen deprivation introduced by the Vancouver Group is still in the testing phase; in Germany 2 trials by the AUO under the auspices of the Deutsche Krebsgesellschaft address this question.

\section{Where Do We Go from Here?}

Health-related quality of life while under hormonal therapy will become an important endpoint. Instruments in the form of questionnaires originate from the EORTC or the SWOG. Presently, 6 questionnaires to measure the quality of life in prostate cancer patients have been developed (tab. 1). Side effects of the treatment itself interfere with these issues [5]. Finally, prognostic factors should be used more often when planning hormonal therapy for metastatic carcinoma of the prostate. Presently, the stage $(\mathrm{N}+$ or $\mathrm{M}+)$ is more or less the only factor considered to be of prognostic relevance at the inception of treatment. Sylvester et al. [6] have nicely demonstrated the difference in the response to maximal androgen blockade depending on whether patients with bone metastases
Table 1. Instruments to measure the quality of life in patients with prostate cacer

\begin{tabular}{lll}
\hline Name & Abbreviation & $\begin{array}{l}\text { Number of } \\
\text { questions }\end{array}$ \\
\hline $\begin{array}{l}\text { UCLA Prostate Cancer Index } \\
\begin{array}{l}\text { Functional Assessment of } \\
\text { Cancer Treatment }- \text { Prostate }\end{array}\end{array}$ & FCI & 20 \\
$\begin{array}{l}\text { Prostate Cancer Treatment } \\
\text { Outcomes Questionnaire }\end{array}$ & PCTOQ & 12 \\
$\begin{array}{l}\text { EORTC Quality } \\
\text { of Life Prostate }\end{array}$ & 41 \\
$\begin{array}{l}\text { Quality of Life Index } \\
\text { Radiumhemmet Scale of } \\
\text { Sexual Function }\end{array}$ & EORTC QLQ PR & 25 \\
\hline
\end{tabular}

belong to a good or poor prognostic group. They have shown that hemoglobin, alkaline phosphatase, pain score, and T-stage are independent prognosticators. If they predict a good prognosis, maximal androgen blockade enhances tumor-specific survival by almost 2 years, in contrast to patients with a poor prognosis where the kind of hormonal treatment did not matter. Presently, endocrine manipulation has no alternative in patients with metastatic carcinoma of the prostate. The principal of androgen suppression still stands, however, its proper employment in the PSA era requires a special focus on aspects like modality, category, prognostic factors, and consideration of the quality-of-life issue including the desire of the patient.

\section{References}

1 Akakura K, Bruchovska N, Goldenberg SL, Rennie PS, Buckley AR, Sullivan LD: Effects of intermittent androgen suppression on androgen-dependent tumors. Cancer 71:2782-2790, 1993

2 Wilson JD: The promiscuous receptor. Prostate cancer comes of age. N Engl J Med 1995;332:1440-1441.
3 Gregory CHW, Kim D, Smith GJ, Mohler F, Mohler $\mathrm{JL}$ : Evidence for androgen receptor-mediated growth of androgen-independent prostate cancer. J Urol 1999;161:abstr 469

4 Ströberg P, Anderström C, Folmerz P: Surgical castration - Can we afford not to do it? Br J Urol 1997;80(suppl 2):276 A.
5 Moinpour CM, Savage MJ, Troxel A: Quality of life in advance prostate cancer: Results of a randomized therapeutical trial. J Natl Cancer Inst 1998; 90:1537-1544.

6 Sylvester RJ, Denis L, de Voogt H: The importance of prognostic factors in the interpretation of two EORTC metastatic prostate cancer trials. Eur Urol 1998;22:134-143 